\title{
Hydrogen-deuterium exchange mass spectrometry reveals the interaction of Fenna-Matthews-Olson protein and chlorosome CsmA protein
}

\author{
Richard Y-C. Huang ${ }^{1, \dagger}$, Jianzhong Wen ${ }^{1,2,3, \dagger}$, Robert E. Blankenship ${ }^{1,2}$, and Michael L. \\ Gross $^{1, *}$ \\ ${ }^{1}$ Department of Chemistry, Washington University in St. Louis, St. Louis, MO 63130 \\ ${ }^{2}$ Department of Biology, Washington University in St. Louis, St. Louis, MO 63130
}

\section{Abstract}

\begin{abstract}
In green-sulfur bacterial photosynthesis, excitation energy absorbed by a peripheral antenna structure known as the chlorosome is sequentially transferred through a baseplate protein to the Fenna-Matthews-Olson (FMO) antenna protein and into the reaction center, which is embedded in the cytoplasmic membrane. The molecular details of the optimized photosystem architecture required for efficient energy transfer are only partially understood. We address here the question of how the baseplate interacts with the FMO protein by applying hydrogen/deuterium exchange coupled with enzymatic digestion and mass spectrometry analysis to reveal the binding interface of the FMO antenna protein and the CsmA baseplate protein. Several regions on the FMO protein, represented by peptides consisting of 123-129, 140-149, 150-162, 191-208 and 224-232, show significant decreases of deuterium uptake after CsmA binding. The results indicate that the CsmA protein interacts with the $\mathrm{Bchl} a \# 1$ side of the FMO protein. A global picture including peptidelevel details for the architecture of the photosystem from green sulfur bacteria can now be drawn.
\end{abstract}

Billions of years of evolution allowed photosynthetic species to achieve not only an optimized structure for an individual light-harvesting complex but also an appropriate architecture for the overall photosystem to facilitate efficient energy transfer and regulation (1). Investigations of the structure and function of the antenna components and their optimized overall architecture are needed to understand their energy-transfer mechanism and to provide a sound basis for the design of artificial and bio-hybrid solar devices. Advances in biochemical and biophysical approaches (e.g., X-ray crystallography, cryo-EM, and ultrafast spectroscopy) have greatly enhanced our understanding of the workings of individual antenna complexes. The exploration of the overall architecture of the photosystem, however, lags behind owing to their complex architecture and the lack of a more complete suite of approaches than is now available to study proteins in complex milieu.

In photosynthetic green-sulfur bacteria, photons are absorbed by the large peripheral chlorosome antenna complex (2), which is located on the cytoplasmic side of the membrane.

\footnotetext{
" To whom correspondence should be addressed: Department of Chemistry, Washington University in St. Louis, Campus Box 1134, St. Louis, MO 63130. Telephone: (314) 935-4814, Fax: (314) 935-7484, mgross@ wustl.edu.

${ }^{\dagger}$ R.Y-C.H. and J.W. contributed equally to this work.

${ }^{3}$ Current address: Howard Hughes Medical Institute, Department of Pharmacology, University of California, San Diego, CA 92093

Supporting Information Available

Supplemental figures are included in the Supporting Information section. This material is available free of charge via the Internet at http://pubs.acs.org.
} 
Chlorosomes are attached to the cytoplasmic membrane through a pigment-protein complex known as a baseplate (3). The baseplate and the Fenna-Matthews-Olson (FMO) antenna protein (4) form a bridge to transfer sequentially the energy collected by chlorosomes to the reaction center (RC). The baseplate consists of the CsmA protein with Bchl $a$ pigments embedded within. The structure of the refolded CsmA protein was determined by NMR, demonstrating that it contains only two small alpha helices connected by a small turn (3).

The chlorosome is one of the largest antenna systems known; it contains hundreds of thousands of $\mathrm{Bchl} c, d$ or $e$ per chlorosome and is enclosed by a lipid monolayer (5). The architecture of chlorosomes has evolved to enable certain organisms to live at extraordinary low-light intensities under which no other phototrophic organism can grow (6). Unlike other light-harvesting antennae, efficient energy transfer is achieved by self-assembly of the Bchl c/d/e pigments in the chlorosome to yield stable structures without the requirement of a scaffold protein (6). Understanding this arrangement is important because it can guide the design of artificial light-harvesting systems. Progress in understanding the chlorosome can occur by taking advantage of recent biochemical and biophysical approaches $(7,8)$.

These recent approaches show that the light energy collected by the Bchl aggregates is funneled to the baseplate protein, which is located at the side of chlorosome closest to the cytoplasmic membrane (9). The baseplate protein is a 2D paracrystalline structure that is believed to consist of CsmA (chlorosome protein A) and Bchl $a$. Chemical crosslinking revealed that CsmA forms oligomers in chlorosomes (10). The NMR structure of apo-CsmA (without bound $\mathrm{Bchl} a$ ) from Chlorobaculum tepidum (59 amino acids) shows a large extent of alpha helical content. The N-terminal helix (6-36), which has the putative Bchl $a$ binding site, is thought to be immersed in the lipid monolayer of the chlorosome, whereas the $\mathrm{C}$ terminal helix (41-49) sticks out of the membrane and may interact with the FMO protein at that point. The existence of the baseplate is predicted to enhance significantly the energytransfer rate from the chlorosome Bchl aggregates to the RC (2) (Figure 1).

The FMO protein, which is located between the baseplate and the cytoplasmic membrane (11), exists as a trimer, with a three-fold symmetry axis perpendicular to the membrane. This water-soluble protein has been a model system for studies aimed at understanding the structural and functional relationships of pigment-binding photosynthetic antenna complexes (12-15). The number of pigments embedded in FMO is important for its function, and recently an $8^{\text {th }} \mathrm{Bchl} a$ was identified in each monomer $(16,17)$. Several lines of evidence suggest that the side of the protein where this $8^{\text {th }} \mathrm{Bchl}$ is located faces the baseplate/ chlorosome $(11,18,19)$.

The connection between the baseplate, the FMO protein, and the RC is likely to be optimized so that excitation energy can be efficiently transferred at high quantum yield. Previous results from SPR studies (20) suggest that the C-terminal region of CsmA, especially the conserved INRNAY residues, interact with the FMO protein. The molecular details of their interactions, however, remain unclear. The interaction region between the FMO and the RC is also unknown, although homology modeling with a divergent FMO protein has suggested a possible binding site (18).

In this paper, we describe the use of hydrogen/deuterium exchange (H/DX) coupled with mass spectrometry (MS) (21-24) to study the interaction interface and dynamics between FMO and CsmA. With H/DX, we followed the relative rates of exchange of amide hydrogens, which are measured on the basis of $\mathrm{m} / \mathrm{z}$, not abundance. Experimental outcomes are a measure of changes in the stability of the hydrogen bonding and the surrounding relative solvent accessibilities of the amides. To achieve resolution at the peptide level of FMO and the complex, we coupled H/DX with enzymatic digestion. The FMO/CsmA 
binding information obtained through H/DX not only provides novel insights into the interaction interfaces between the proteins but further confirms the orientation of FMO in the photosystem.

\section{Materials and Methods}

\section{Materials}

The FMO protein from Chlorobaculum tepidum was purified following a previously described protocol (17). The CsmA C-terminal peptide containing 19 amino acids (MRINRNAYGSMGGGSLRGS) was purchased from Biomatik LLC (Wilmington, Delaware).

Potassium chloride, calcium chloride, and HEPES hemisodium salt [ $\mathrm{N}$-(2hydroxyethyl)piperazine- $N^{\prime}$-(2-ethanesulfonic acid) hemisodium salt] were purchased from Sigma-Aldrich (St.Louis, MO). Deuterium oxide was purchased from Cambridge Isotope Laboratories Inc (Andover, MA). Immobilized pepsin on agarose was purchased from Pierce (Rockford, IL).

\section{H/DX Protocol}

To achieve good signal-to-noise ratios for the protein signal of FMO, the final concentration of FMO was optimized to $6 \mu \mathrm{M}$, and the FMO:CsmA ratio was 1:20 to ensure the interaction was saturated.

For global H/DX measurements, $6 \mu \mathrm{L}$ of protein was mixed with $74 \mu \mathrm{L}$ of $\mathrm{D}_{2} \mathrm{O}$ buffer $(92.5 \% \mathrm{D} 2 \mathrm{O})(10 \mathrm{mM}$ HEPES, $\mathrm{pH}=7.0,150 \mathrm{mM} \mathrm{KCl})$ and held for various times at $25^{\circ} \mathrm{C}$ before quenching by adding $2 \mu \mathrm{L}$ of $1 \mathrm{M} \mathrm{HCl}$ to lower the $\mathrm{pH}$ to 2.5 . To generate the FMO complex with CsmA a modified condition was employed as that used by Miller and coworkers (20); the FMO and the CsmA peptide were incubated $4 \mathrm{~h}$ at room temperature in the dark (in $20 \mathrm{mM}$ Tris/ $\mathrm{HCl}, \mathrm{pH}=8.0$, with $150 \mathrm{mM} \mathrm{KCl}$ ) and then kept at $4{ }^{\circ} \mathrm{C}$ overnight before conducting the H/DX.

For the peptide-level H/DX, the quenched solution was added with $15 \mu \mathrm{L}$ of immobilized pepsin on agarose. The digestion was conducted on ice for $3 \mathrm{~min}$. After digestion, the beads were quickly centrifuged ( $2-3 \mathrm{~s}$ ) to pellet the pepsin beads, and the supernatant was analyzed by LC/MS.

\section{LC-ESI/MS Analysis with a Q-TOF Mass Spectrometer}

The quenched protein solution from global-protein and peptide-level H/DX experiments was loaded onto a C18 guard column $(1 \mathrm{~mm} \times 15 \mathrm{~mm}$, Optimize Technologies, Oregon, City, OR), pre-equilibrated with $100 \mu \mathrm{L}$ of $0.2 \%$ formic acid in water $\left(0{ }^{\circ} \mathrm{C}\right)$, and washed with $300 \mu \mathrm{L}$ of $0.2 \%$ formic acid in water $\left(0{ }^{\circ} \mathrm{C}\right)$ to back-exchange the labile side-chain functional groups of the protein and the peptides. The peptides and any remaining protein were eluted with a fast gradient in 8 min starting from $0 \%$ solvent B to $90 \%$ solvent B at 40 $\mathrm{uL} / \mathrm{min}$ (Waters nanoACQUITY UPLC, Manchester, U.K; solvent A, 95\% water and 5\% acetonitrile containing $0.3 \%$ formic acid; solvent B, $5 \%$ water and $95 \%$ acetonitrile containing $0.3 \%$ formic acid). To minimize back exchange, all LC connection lines, injection valve, and sample loop were immersed in water-ice slush $\left(0^{\circ} \mathrm{C}\right)$.

All ESI mass spectra were acquired in the positive-ion mode on a Maxis (Bruker, Billerica, MS) Q-TOF spectrometer equipped with a standard ESI source. The capillary voltage was $3.6 \mathrm{kV}$, the end-plate offset $-500 \mathrm{~V}$, and the dry gas flow rate and temperature at $4 \mathrm{~L} / \mathrm{min}$ and $180^{\circ} \mathrm{C}$, respectively. The MS profiles used for transmission were as follows: funnel RF, 
$400 \mathrm{~V}_{\mathrm{pp}}$; multipole RF, $400 \mathrm{~V}_{\mathrm{pp}}$; collision cell voltage, $10 \mathrm{~V}$; collision $\mathrm{RF}, 3000 \mathrm{~V}_{\mathrm{pp}}$; transfer time, $140 \mathrm{us}$; ion cooler $\mathrm{RF}, 800 \mathrm{~V}_{\mathrm{pp}}$; pre-pulse storage, $25 \mu \mathrm{s}$.

\section{LC-ESI-MS/MS Analysis of Protein Digest}

Peptides produced by pepsin cleavage of FMO were identified by their accurate masses and product-ion sequencing on a LTQ-FTMS instrument (Thermo, San Jose, CA). The peptide solution from pepsin digestion of $100 \mathrm{pmol}$ FMO was loaded onto a C18 column, $75 \mu \mathrm{m}$ diameter, which was prepared with a laser-based column puller (Sutter Instruments, Novato, $\mathrm{CA}$ ) and packed with $12 \mathrm{~cm}$ of Magic C18AQ reverse phase media (Michrom Bioresources, Auburn, CA). The peptides were separated over 70 min by using an Eksigent (Dublin, CA) NanoLC-1D column with an LC gradient from 3 to $97 \%$ acetonitrile containing $0.1 \%$ formic acid at $260 \mathrm{~nL} / \mathrm{min}$. The solution was sprayed into the mass spectrometer by using a PicoView PV-500 nanospray source (New Objective, Woburn, MA) attached to the LTQFTMS instrument. One full mass spectral acquisition in the FT mode, operating at a mass resolving power of 100,000 at $\mathrm{m} / \mathrm{z}$ 400, triggered six scans of MS/MS whereby the most abundant precursor ions were activated for sequencing. The MS/MS experiments carried out in the LTQ instrument utilized wide-band activation and dynamic exclusion. The production spectra (MS/MS) data were centroided during the acquisition.

\section{Mascot Database Search}

Thermo RAW files were processed by using extract_msn (2007 version 4.0, Thermo Fisher, San Jose, CA) with a grouping tolerance of $0.8 \mathrm{Da}$, an intermediate scan setting of 1 , and a minimum of 1 scan per group. The NCBI non-redundant database (version 20090623, restricted to Other Bacteria) was searched by using MASCOT 2.2.06 (Matrix Science, Oxford, U.K.) with the following settings: enzyme, none; MS tolerance, $10 \mathrm{ppm}$; MS/MS tolerance, $0.8 \mathrm{Da}$; maximum number of missed cleavages, 3 ; peptide charge of $1+, 2+$ and $3+$; oxidation of methionine was included as a variable modification.

\section{Data Analysis}

For global-protein H/DX experiments, the mass spectrum at each H/D exchange time point was deconvoluted by using MagTran 1.03 (Amgen, Thousand Oaks, CA). The deuterium uptake levels at each time point were taken as the average differences of the centroided masses of the undeuterated protein and the deuterated protein. The protein deuterium uptake was not corrected for back-exchange because the time from quench to observation in the mass spectrometer was less than $6 \mathrm{~min}$, and only relative deuterium levels needed to be compared in all experiments. All of the experiments were conducted in triplicate.

For peptide-level H/DX experiments, each mass list from three experimental trials was extracted from their individual spectra as an $\mathrm{x}, \mathrm{y}$ file (x: mass-to-charge ratio; $\mathrm{y}$ : intensity). The centroid and width of the deuterium-containing isotopic distribution for each peptide was analyzed using HX-Express software (25).

\section{Kinetic Modeling}

The global protein kinetic data were fit with a fixed-rate-constant binning model by using MathCAD (Math-Soft. Inc. Cambridge, MA) in which the root mean square (RMS) was minimized $(26,27)$. Four rate constants $\left(k=10,1,0.1,0.01 \mathrm{~min}^{-1}\right)$ were selected because the kinetic data span $0.5-60 \mathrm{~min}$, hence the brackets of $10 \mathrm{~min}^{-1}$ (fast exchangers, half-life $\sim 0.07 \mathrm{~min}$ ) and $0.01 \mathrm{~min}^{-1}$ (slow exchangers, half-life $\sim 69 \mathrm{~min}$ ). Three trials were fit separately, and the results were averaged and reported with standard deviations. 


\section{Results}

\section{H/DX kinetics of FMO and FMO/CsmA}

Previous SPR studies (20) suggest that the interaction between the FMO protein and the chlorosome CsmA protein is primarily on the C-terminal helix of CsmA, especially with the conserved INRNAY residues (28). The interaction regions on FMO, however, remain unclear. Given that the protein conformation and the relative solvent accessibilities of FMO will change upon the binding of CsmA, we chose a measurement of the H/DX kinetics of FMO alone and as the FMO/CsmA complex to examine globally their interaction and dynamics (Figure 2). Given the highly hydrophobic nature of CsmA, we utilized for interaction a peptide representing the C-terminal region of CsmA, which contains 19 amino acids (MRINRNAYGSMGGGSLRG) and the highly conserved INRNAY motif.

Each FMO monomer has 348 exchangeable amide protons (excluding 19 prolines). Because the percentage of $\mathrm{D}_{2} \mathrm{O}$ in the experiment was $92.5 \%$, the maximum number of observable exchange events was 322 . After $10 \mathrm{~min}$ of H/DX, the mass of FMO shifted by $89 \pm 1 \mathrm{Da}$, indicating that $\sim 27 \%$ of the amides exchanged at this time point. Even after $60 \mathrm{~min}$ of H/ DX, the extent of exchange had only increased to $\sim 30 \%$ ( $96 \pm 1$ amides) at a time when the exchange had leveled off and became relatively constant. The small difference is consistent with a compact and stable FMO trimer in solution. Approximately $2 / 3$ of the amides of each monomer are protected because they form hydrogen bonds, or exist inside each monomer, or they are involved in forming a compact trimer. The remaining $1 / 3$ of the amides are solventexposed and highly dynamic.

In the presence of CsmA peptide, the number of amides undergoing H/DX decreased to $80 \pm$ 2 after 10 min of exchange, indicating that $\sim 9$ amides now exchange more slowly as a consequence of CsmA binding. The number of amides affected by the CsmA binding is relatively small, consistent with the small size of the CsmA peptide and its limited effect on (i) overall FMO stability, (ii) the extent of hydrogen bonding, and (iii) the solvent accessibility of FMO.

To understand better how CsmA binding affects the exchange rate in a quantitative way, we fit the kinetic curve with four exchange rate-constant bins $\left(\mathrm{k}=10,1,0.1,0.01 \mathrm{~min}^{-1}\right)$ (Table 1). The results show that apo FMO (native FMO trimer without the binding of CsmA) has $25 \pm 3$ sites that exchange with a rate constant of $10 \mathrm{~min}^{-1}$, whereas after binding with the CsmA peptide (holo FMO), FMO has $29 \pm 2$ amides that exchange with the same rate constant. Although the number of amides exchanging at this rate constant are similar for the apo and holo states, there are significant differences for those amides that exchange with smaller exchange rate constants. For those exchanging with rate constants of $1 \mathrm{~min}^{-1}$ and $0.1 \mathrm{~min}^{-1}$, the numbers of exchangeable amides for holo FMO are lower than for apo by $\sim 10$. Some of these sites exchanged with the smallest rate constant of $0.01 \mathrm{~min}^{-1}$ as can be seen for the holo state, for which $15 \pm 1$ sites exchanged. For the apo state, only $4 \pm 1$ amides exchanged with this smallest rate constant. These results indicate that CsmA binding slows down the exchange at some sites of the FMO protein with medium exchange rate constants and causes FMO either to form a more rigid secondary structure or to lose solvent accessibility at certain amide sites.

\section{The FMO/CsmA binding interface}

Global H/DX of the FMO/CsmA complex shows clear uptake differences compared to apo FMO. To locate the interaction regions, we conducted H/DX at the peptide level by using pepsin digestion and LC/MS analysis. We expect that changes of the peptide-level deuterium uptake of FMO in the presence of CsmA can locate regions implicated in CsmA binding. 
We used the same experimental conditions for H/DX as for the global protein measurements. After $10 \mathrm{~min}$ of exchange, the H/DX at the protein level had become relatively constant; further, there is a significant difference in D uptake between apo and holo FMO at this time. We were able to identify FMO peptic peptides, as confirmed by accurate mass measurement and tandem-MS sequencing that show sequence coverage of $80 \%$ (Figure 3). This high coverage ensures that we can localize regional (peptide-level) changes associated with CsmA binding.

There are approximately 10 amides on the FMO protein that are affected by CsmA binding. We found five peptic FMO peptides (123-129, 140-149, 150-162, 191-208, and 224-232) that show decreased deuterium uptake upon the CsmA binding. The level of deuterium uptake difference for each of these five peptides is generally small ( 2D), which is consistent with the total difference in H/DX measured on the global level. To examine these differences in a comparable way, we converted them to the relative deuterium uptake based on equation 1 and plotted them as a function of peptic peptides (Figure 4).

$$
\% \mathrm{D}=\frac{\text { deuterium uptake }}{\left(\# \text { aa's }-\mathrm{N}_{\text {term }}-\text { \#Pro }\right)}
$$

In the equation, $\% \mathrm{D}$ is the relative deuterium uptake for each peptide; \#aa's is the total exchangable hydrogens on each peptide; $\mathrm{N}_{\text {term }}$ is the number of hydrogens on the $\mathrm{N}$ terminus of the peptide.

The plot (Figure 4) shows that three regions of the FMO represented by peptides 140-149, 150-162, and 224-232 undergo decreased H/DX in the presence of CsmA by at least 10\% with respect to the apo state. Two other regions (represented by peptides 123-129 and 191-208) show smaller changes, 5\% differences. All the other detected peptic peptides show virtually no difference with and without CsmA binding. Although we didn't examine the extent of exchange on the CsmA, given that the CsmA peptide utilized in this study is short and specific, our results conclude that the $\mathrm{C}$-terminal region of $\mathrm{CsmA}$, indeed interacts with FMO.

\section{FMO structural mapping}

To locate the regions on FMO that are implicated in binding with CsmA, we mapped the five peptic peptides onto the X-ray crystal structure of FMO from Chlorobaculum tepidum (PDB: 3ENI) (16) (Figure 5). Interestingly, all sites that exchange differently are located on one side of the FMO protein, which is referred to as the Bchl $a \# 1$ side of the protein (shown in red) (11). This finding agrees well with results from a previous study on the membrane orientation of FMO in green-sulfur bacteria (11); those results also show the Bchl $a \# 1$ side of the FMO interacts with the chlorosome. This study of the peptide-level H/DX further confirms and refines the spatial resolution to a region extending over five peptides of FMO.

On the basis of the relative peptide-level deuterium uptakes, we can identify three categories of deuterium uptake for FMO: (1) regions showing large extents of deuterium uptake (>30\%) and significant differences when CsmA binds; (2) regions showing small extents of deuterium uptake $(<10 \%)$ and no significant differences in the presence and absence of CsmA; and (3) regions showing large extents of deuterium uptake (>30\%) but no significant differences in the absence or presence of CsmA. These results, when mapped onto the structure of FMO (Figure 6), show that category \#3 regions include, for example, peptide 2-17 (shown in black in Figure 5 and Figure 6), which is located at or near flexible helices or loops mainly on the outer surface of FMO. Those category \#2 regions (e.g., peptide 
233-239) are located at or near the interface of the FMO trimer (shown in blue in Figure 5 and Figure 6).

\section{Discussion}

One important link in the green-sulfur bacterial photosystem is a light-harvesting chlorosome that absorbs light and transports the energy through a baseplate protein and the FMO protein to the reaction center where energy conversion takes place. A gap existed is our understanding of the interaction between the baseplate and FMO and motivated this study.

CsmA, a major component in the baseplate, contains the putative Bchl $a$ binding site in its $\mathrm{N}$-terminal region and may be immersed in the lipid monolayer of the chlorosome, whereas a region near its $\mathrm{C}$-terminal helix protrudes from the membrane and may interact with the FMO protein. A previous SPR study (20) shows that the conserved residues (INRNAY) of the C-terminal region of CsmA interact with the FMO protein.

To investigate this interaction, we chose H/DX because it is a general approach, "marking" all the amino acids except proline and covering nearly the entire protein backbone. H/DX is sensitive to the solution environment surrounding the protein, enabling one to capture even minor changes in protein conformation and solvent accessibility caused by the changes in hydrogen bonding occurring when peptides bind to proteins. In this study, we used a model synthetic peptide of 19 amino acids (MRINRNAYGSMGGGSLRG) from the C-terminal region of CsmA to probe the FMO/CsmA interaction. The peptide, which contains the conserved INRNAY region, forms a small alpha helix, as does CsmA itself, and interacts with the FMO protein (3). Global-level H/DX shows that only 10 amides of FMO are affected by the CsmA binding. Although the stoichiometry and the binding affinity between FMO and CsmA are unknown, this small extent of exchange in a large protein makes difficult a determination of the binding affinity by PLIMSTEX (Protein Ligand Interaction by Mass Spectrometry, Titration and H/D Exchange) at the protein level $(26,27)$. Nevertheless, their interaction should be strong in vivo possibly because CsmA forms oligomers in the baseplate (10), and the oligomeric CsmA interacts more strongly with FMO than does the monomer. In addition, the tail of the $8^{\text {th }} \mathrm{Bchl} a$ in the FMO protein may play a role in vivo by interacting with the carotenoid/Bchl $a$ in the CsmA or with hydrophobic regions of CsmA (17). The involvement of oligomeric states further complicates determining a relevant affinity by PLIMSTEX or other methods.

Peptide-level H/DX affords further refinement of the binding interfaces between FMO and CsmA. Five regions of FMO, represented by peptides 123-129, 140-149, 150-162, 191-208, and 224-232, show clear decreases of relative deuterium uptake in the presence of CsmA. Interestingly, these regions are all located on the $\mathrm{Bchl} a \# 1$ side of the FMO, and the outcome agrees well with the previous finding that the baseplate interacts with the Bchl $a \# 1$ side of the FMO $(11,18)$. Moreover, our results also localize the C-terminal region of CsmA that play an important role in FMO/CsmA interaction.

\section{Supplementary Material}

Refer to Web version on PubMed Central for supplementary material.

\section{Acknowledgments}

We thank Dr. Henry Rohrs for assistance with the LTQ-FT analysis. 
Funding: Funding was provided by the National Center for Research Resources (NCRR) of the National Institutes of Health (grant no. 2P41RR000954) to M.L.G. and the U.S. Department of Energy Grant DE-FG02-7ER15846 to R.E.B.

\section{Abbreviations}

$\begin{array}{ll}\text { FMO } & \text { Fenna-Matthews-Olson } \\ \text { RC } & \text { reaction center } \\ \text { ESI } & \text { electrospray ionization } \\ \text { H/DX } & \text { hydrogen/deuterium exchange } \\ \text { HPLC } & \text { high performance liquid chromatography } \\ \text { Q-TOF } & \text { quadrupole time-of-flight }\end{array}$

\section{References}

1. Blankenship, RE. Molecular mechanism of photosynthesis. Blackwell Science; Oxford, UK: 2003.

2. Oostergetel G, van Amerongen H, Boekema E. The chlorosome: a prototype for efficient light harvesting in photosynthesis. Photosynthesis Research. 2010; 104:245-255. [PubMed: 20130996]

3. Pedersen, Ms; Underhaug, J.; Dittmer, J.; Miller, M.; Nielsen, NC. The three-dimensional structure of CsmA: A small antenna protein from the green sulfur bacterium Chlorobium tepidum. FEBS letters. 2008; 582:2869-2874. [PubMed: 18652828]

4. Tronrud DE, Schmid MF, Matthews BW. Structure and X-ray amino acid sequence of a bacteriochlorophyll a protein from Prosthecochloris aestuarii refined at 1.9 ?. resolution. Journal of Molecular Biology. 1986; 188:443-454. [PubMed: 3735428]

5. Beatty JT, Overmann J, Lince MT, Manske AK, Lang AS, Blankenship RE, Van Dover CL, Martinson TA, Plumley FG. An obligately photosynthetic bacterial anaerobe from a deep-sea hydrothermal vent. Proceedings of the National Academy of Sciences of the United States of America. 2005; 102:9306-9310. [PubMed: 15967984]

6. Blankenship, RE.; Matsuura, K. Antenna Complexes from Green Photosynthetic Bacteria. In: Green, BR.; Parson, WW., editors. Light-Harvesting Antennas. Kluwer; 2003. p. 195-217.

7. Ganapathy S, Oostergetel GT, Wawrzyniak PK, Reus M, Gomez Maqueo Chew A, Buda F, Boekema EJ, Bryant DA, Holzwarth AR, de Groot HJM. Alternating syn-anti bacteriochlorophylls form concentric helical nanotubes in chlorosomes. Proceedings of the National Academy of Sciences. 2009; 106:8525-8530.

8. Furumaki S, Vacha F, Habuchi S, Tsukatani Y, Bryant DA, Vacha M. Absorption Linear Dichroism Measured Directly on a Single Light-Harvesting System: The Role of Disorder in Chlorosomes of Green Photosynthetic Bacteria. Journal of the American Chemical Society. 2011; 133:6703-6710. [PubMed: 21476570]

9. Pedersen M, Linnanto J, Frigaard N-U, Nielsen N, Miller M. A model of the protein-pigment baseplate complex in chlorosomes of photosynthetic green bacteria. Photosynthesis Research. 2010; 104:233-243. [PubMed: 20077007]

10. Li H, Frigaard N-U, Bryant DA. Molecular Contacts for Chlorosome Envelope Proteins Revealed by Cross-Linking Studies with Chlorosomes from Chlorobium tepidum. Biochemistry. 2006; 45:9095-9103. [PubMed: 16866355]

11. Wen J, Zhang H, Gross ML, Blankenship RE. Membrane orientation of the FMO antenna protein from Chlorobaculum tepidum as determined by mass spectrometry-based footprinting. Proceedings of the National Academy of Sciences. 2009; 106:6134-6139.

12. Wen J, Harada J, Buyle K, Yuan K, Tamiaki H, Oh-oka H, Loomis RA, Blankenship RE. Characterization of an FMO Variant of Chlorobaculum tepidum Carrying Bacteriochlorophyll a Esterified by Geranylgeraniol. Biochemistry. 2010; 49:5455-5463. [PubMed: 20521767] 
13. Larson C, Seng C, Lauman L, Matthies H, Wen J, Blankenship R, Allen J. The three-dimensional structure of the FMO protein from Pelodictyon phaeum and the implications for energy transfer. Photosynthesis Research. 2011; 107:139-150. [PubMed: 21181557]

14. Engel GS, Calhoun TR, Read EL, Ahn T-K, Mancal T, Cheng Y-C, Blankenship RE, Fleming GR. Evidence for wavelike energy transfer through quantum coherence in photosynthetic systems. Nature. 2007; 446:782-786. [PubMed: 17429397]

15. Panitchayangkoon G, Hayes D, Fransted KA, Caram JR, Harel E, Wen J, Blankenship RE, Engel GS. Long-lived quantum coherence in photosynthetic complexes at physiological temperature. Proceedings of the National Academy of Sciences. 2010; 107:12766-12770.

16. Tronrud D, Wen J, Gay L, Blankenship R. The structural basis for the difference in absorbance spectra for the FMO antenna protein from various green sulfur bacteria. Photosynthesis Research. 2009; 100:79-87. [PubMed: 19437128]

17. Wen J, Zhang H, Gross ML, Blankenship RE. Native Electrospray Mass Spectrometry Reveals the Nature and Stoichiometry of Pigments in the FMO Photosynthetic Antenna Protein. Biochemistry. 2011; 50:3502-3511. [PubMed: 21449539]

18. Wen J, Tsukatani Y, Cui W, Zhang H, Gross ML, Bryant DA, Blankenship RE. Structural model and spectroscopic characteristics of the FMO antenna protein from the aerobic chlorophototroph, Candidatus Chloracidobacterium thermophilum. Biochimica et Biophysica Acta (BBA) Bioenergetics. 2010; 1807:157-164.

19. Schmidtam Busch M, Müh F, El-Amine Madjet M, Renger T. The Eighth Bacteriochlorophyll Completes the Excitation Energy Funnel in the FMO Protein. The Journal of Physical Chemistry Letters. 2011; 2:93-98.

20. Pedersen M, Borch J, Højrup P, Cox R, Miller M. The light-harvesting antenna of Chlorobium tepidum: Interactions between the FMO protein and the major chlorosome protein CsmA studied by surface plasmon resonance. Photosynthesis Research. 2006; 89:63-69. [PubMed: 16915355]

21. Konermann L, Pan J, Liu Y-H. Hydrogen exchange mass spectrometry for studying protein structure and dynamics. Chemical Society Reviews. 2011; 40:1224-1234. [PubMed: 21173980]

22. Engen JR. Analysis of Protein Conformation and Dynamics by Hydrogen/Deuterium Exchange MS. Analytical Chemistry. 2009; 81:7870-7875. [PubMed: 19788312]

23. Englander S. Hydrogen exchange and mass spectrometry: A historical perspective. Journal of The American Society for Mass Spectrometry. 2006; 17:1481-1489. [PubMed: 16876429]

24. Chalmers MJ, Busby SA, Pascal BD, West GM, Griffin PR. Differential hydrogen/deuterium exchange mass spectrometry analysis of protein-ligand interactions. Expert Review of Proteomics. 2011; 8:43-59. [PubMed: 21329427]

25. Weis D, Engen J, Kass I. Semi-automated data processing of hydrogen exchange mass spectra using HX-Express. Journal of The American Society for Mass Spectrometry. 2006; 17:1700-1703. [PubMed: 16931036]

26. Zhu MM, Rempel DL, Gross ML. Modeling data from titration, amide H/D exchange, and mass spectrometry to obtain protein-ligand binding constants. J Am Soc Mass Spectrom. 2004; 15:388397. [PubMed: 14998541]

27. Zhu MM, Chitta R, Gross ML. PLIMSTEX: a novel mass spectrometric method for the quantification of protein-ligand interactions in solution. Int J Mass Spectrom. 2005; 240:213-220.

28. Blankenship, RE.; Olson, JM.; Miller, M. Antenna Complexes from Green Photosynthetic Bacteria. In: Blankenship, RE.; Madigan, MT.; Bauer, CE., editors. Anoxygenic Photosynthetic Bacteria. 1995. p. 399-435. 

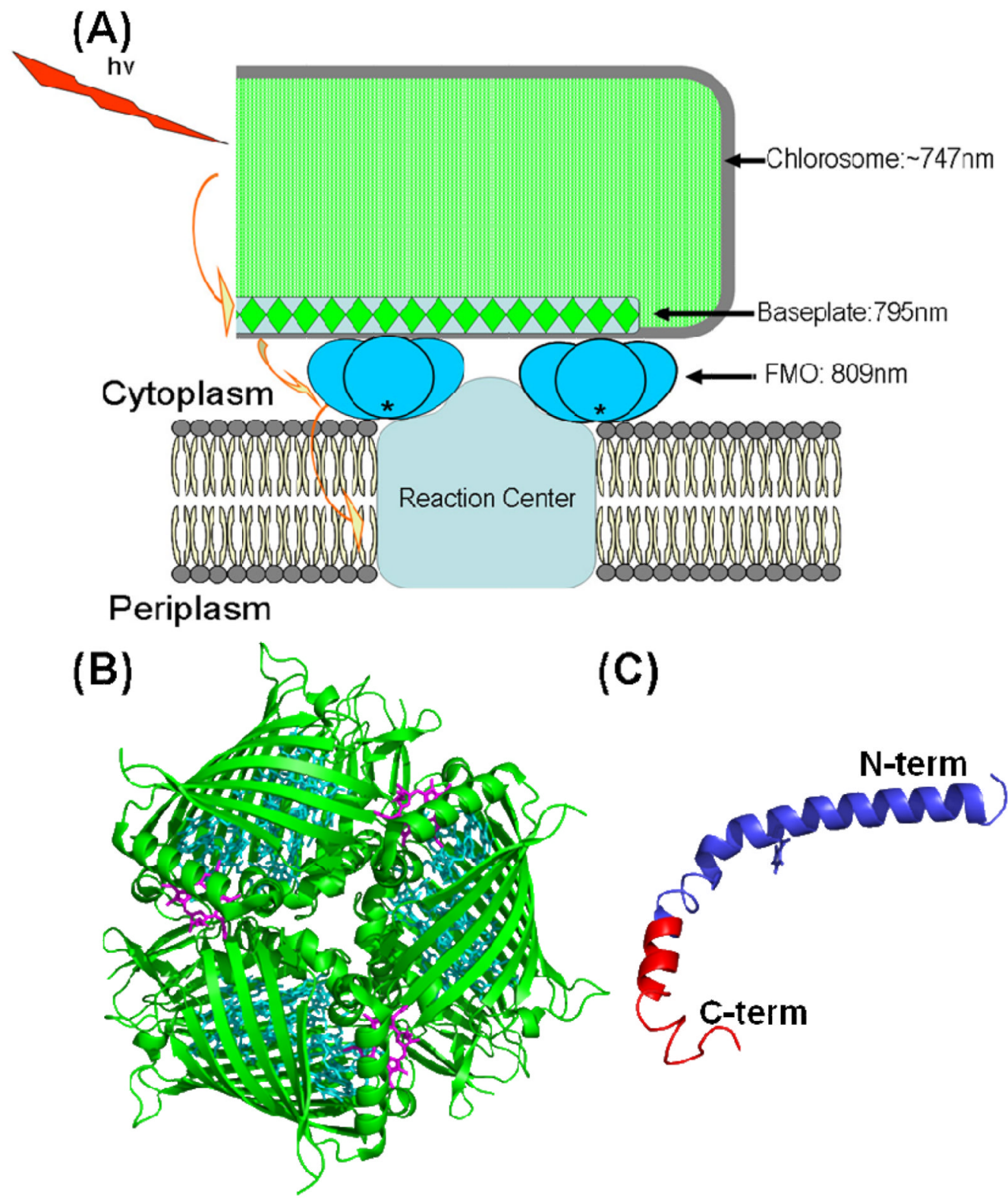

(C)

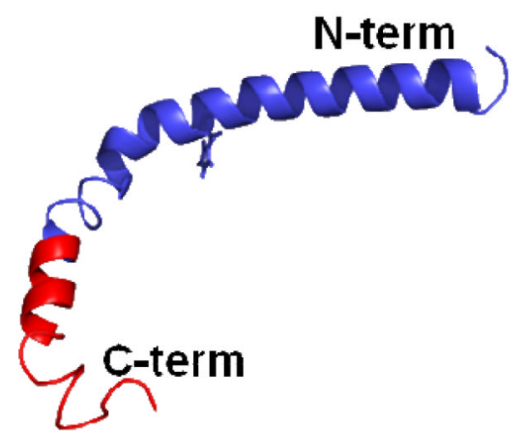

Figure 1.

Structure model of the photosystem (A), the FMO trimer (B) and the CsmA from baseplate (C). The synthetic peptide of the C-terminal region of CsmA

(MRINRNAYGSMGGGSLRGS) used in this study is shown in red. 


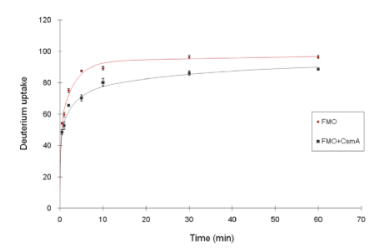

Figure 2.

H/DX kinetics for FMO from Chlorobaculum tepidum. Apo-FMO (diamonds, dark red) shows more extensive D uptake than does holo FMO (CsmA:FMO, 20:1) (squares, black). The fitted curves are shown as solid lines. 


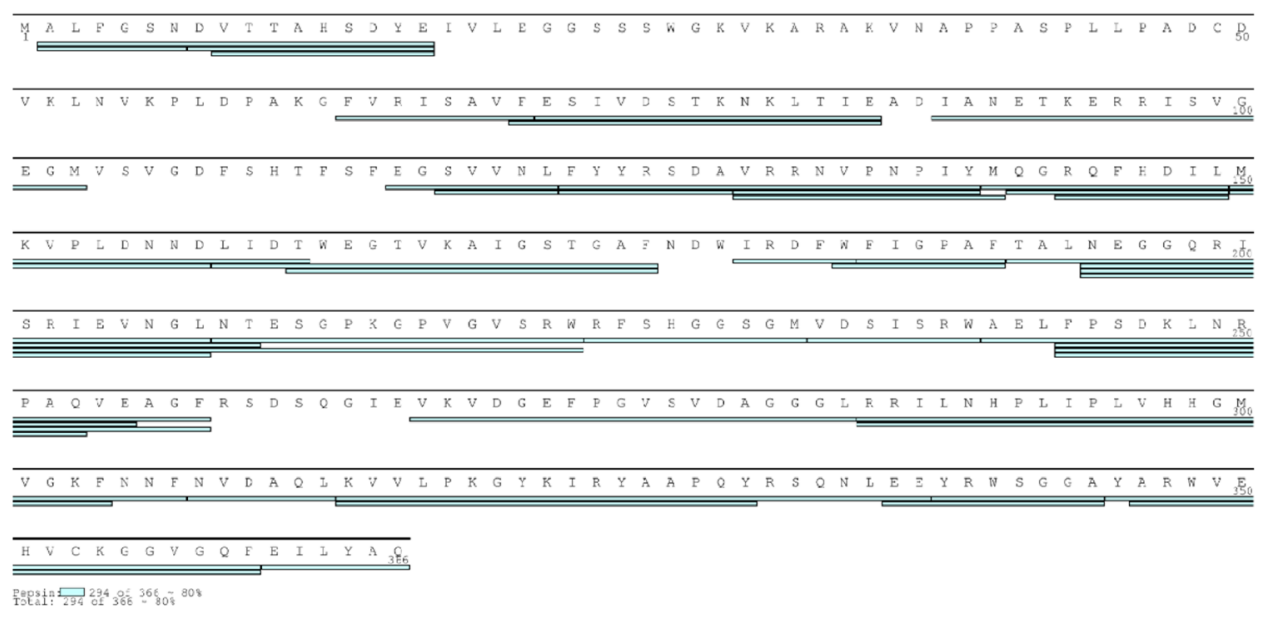

Figure 3.

Sequence coverage ( $\sim 80 \%)$ of peptic peptides from FMO achieved in a peptide-level H/DX study. 

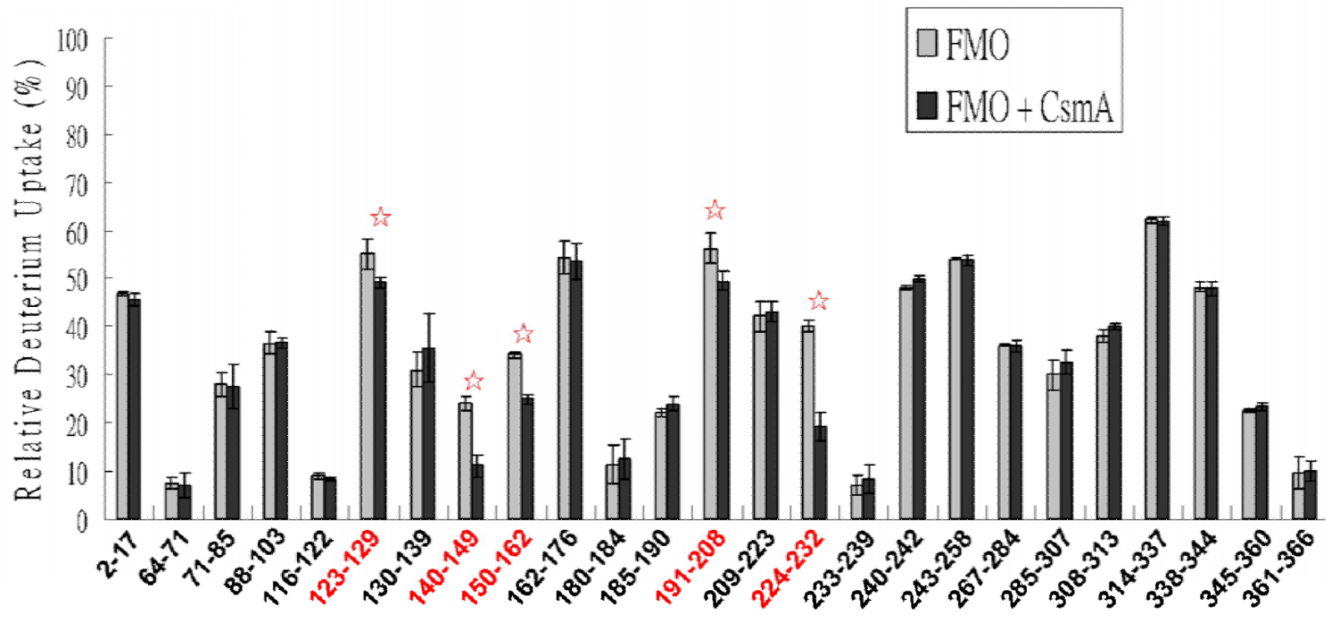

Figure 4.

Relative deuterium uptakes for peptic peptides from $\mathrm{N}$ to C-terminus of FMO after $10 \mathrm{~min}$ of H/DX. Peptide regions showing significant differences in D uptake (> 5\% difference) in the presence of CsmA are labeled in red font and marked with red stars. 

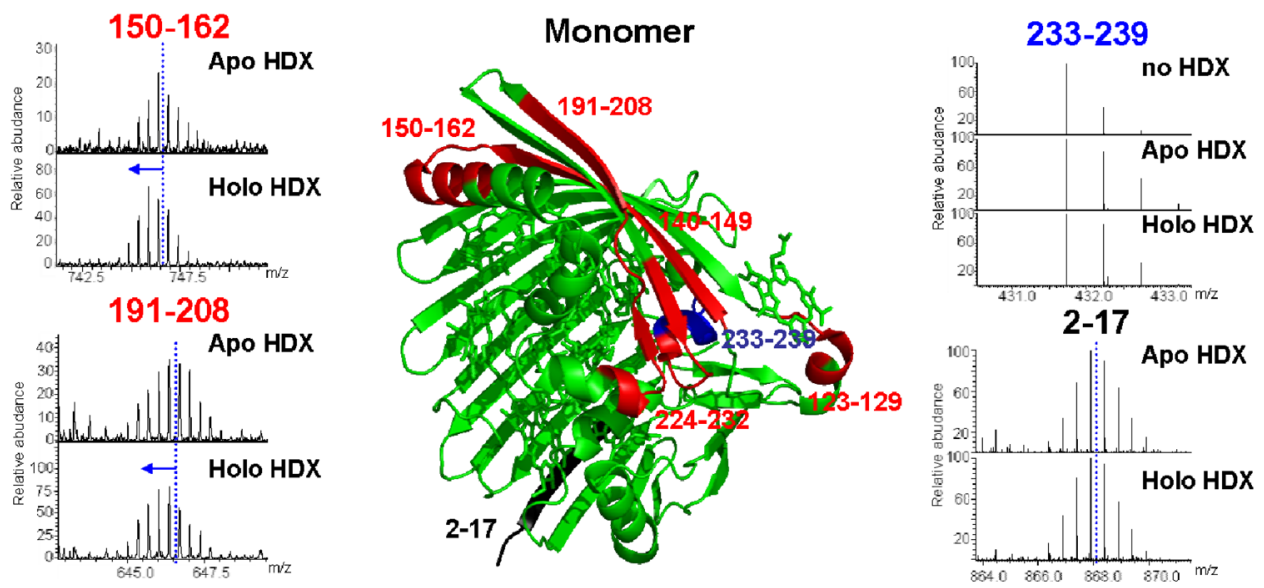

Figure 5.

FMO monomer structure mapping (PDB: 3ENI) with the deuterium uptake patterns. Peptide regions of FMO undergoing significant $\mathrm{D}$ uptake differences between apo and holo states are in red. Peptide 233-239 located in the center of the trimer underwent low D uptake (blue), whereas peptide 2-17 located on the outer shell of the protein underwent relatively extensive D uptake (black). 

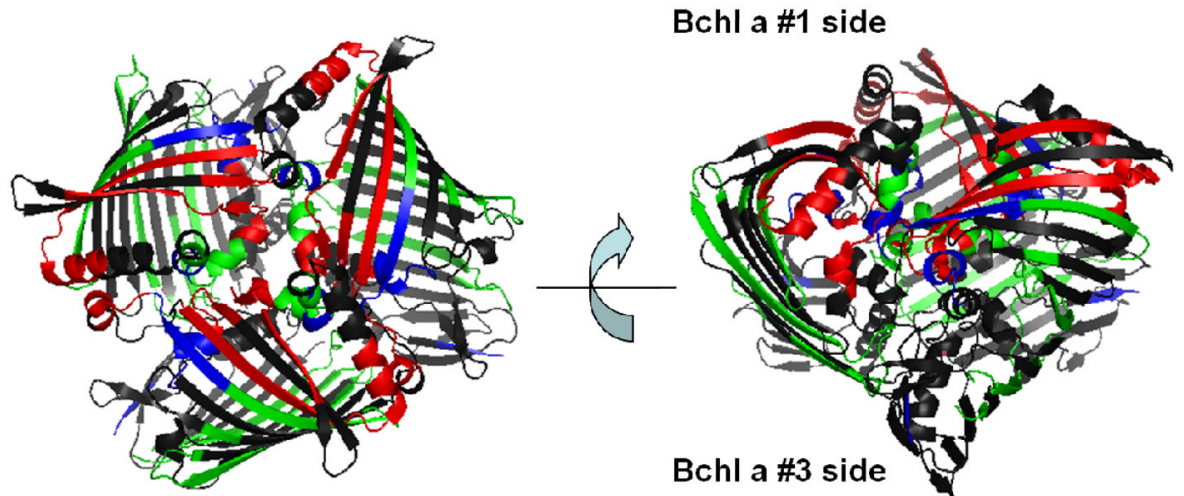

$\square>30 \% \mathrm{D}$ uptake, significant $\mathrm{D}$ uptake difference when CsmA was bound

$>30 \%$ D uptake

$\square<10 \%$ D uptake

Figure 6.

Map of H/DX on the FMO trimer structure (PDB: 3ENI). Peptide regions showing relatively extensive H/DX (>30\%) and significant differences on D uptake when CsmA was bound are in red. Peptide regions showing relatively low D uptake $(<10 \%)$ are in blue. Peptide regions undergoing relatively extensive H/DX $(>30 \%)$ are in black. 
(A)

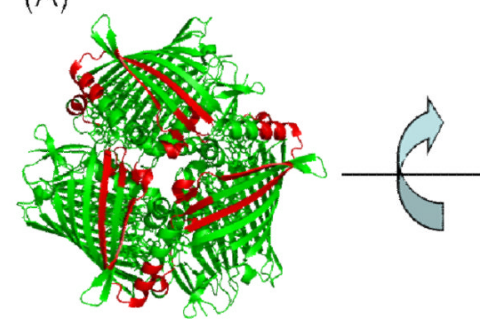

(B)

\section{FMO Trimer}

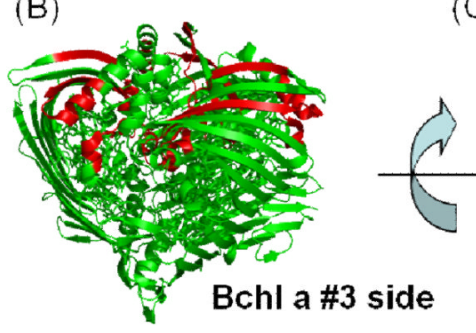

(C)

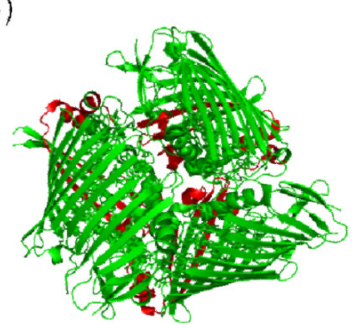

Figure 7.

Orientation of the FMO trimer structure (PDB: 3ENI). Peptide regions undergoing significantly different $\mathrm{D}$ uptake in the presence of CsmA are in red. (A) Top view of the FMO trimer. (B) Side view of FMO trimer. (C) Bottom view of FMO trimer. 


\section{Table 1}

Numbers of amide hydrogen undergoing deuterium exchange for apo and holo FMO. The kinetic modeling used four fixed exchange rate constants and "binned" the number of amides with respect to the rate constants.

\begin{tabular}{|l|c|c|c|c|}
\hline Kinetic Fit & \multicolumn{4}{|c|}{ Number of H's per fixed-rate-constant bin } \\
\hline k $\left(\mathbf{m i n}^{-1}\right)$ & $\mathbf{1 0}$ & $\mathbf{1}$ & $\mathbf{0 . 1}$ & $\mathbf{0 . 0 1}$ \\
\hline apo & $25 \pm 3$ & $29 \pm 4$ & $39 \pm 3$ & $4 \pm 1$ \\
\hline holo & $29 \pm 2$ & $20 \pm 2$ & $29 \pm 1$ & $15 \pm 1$ \\
\hline
\end{tabular}

